\title{
Intestinal Transplantation in Children
}

\section{A Review of Immunotherapy Regimens}

\author{
Navdeep S. Nayyar, ${ }^{1}$ William McGhee, ${ }^{2,3}$ Dolly Martin,${ }^{2}$ Rakesh Sindhi, ${ }^{1,2}$ Kyle Soltys, ${ }^{1,2}$ Geoffrey Bond ${ }^{1,2}$ and \\ George V. Mazariegos ${ }^{1,2}$ \\ 1 Hillman Center for Pediatric Transplantation, Children's Hospital of Pittsburgh of UPMC, Pittsburgh, Pennsylvania, USA \\ 2 Thomas E. Starzl Transplantation Institute, Pittsburgh, Pennsylvania, USA \\ 3 Department of Pharmacy, Children's Hospital of Pittsburgh of UPMC, Pittsburgh, Pennsylvania, USA
}

\section{Contents}

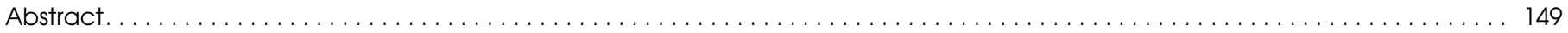

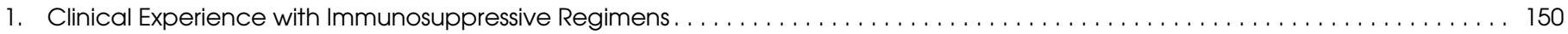

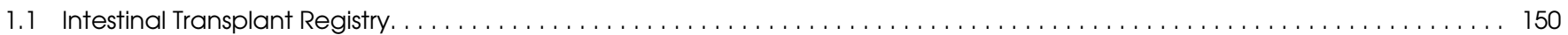

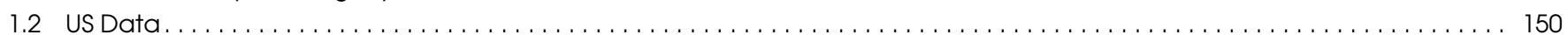

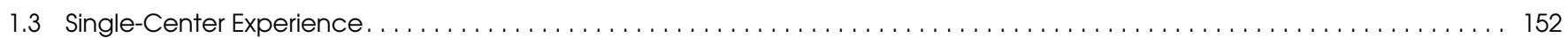

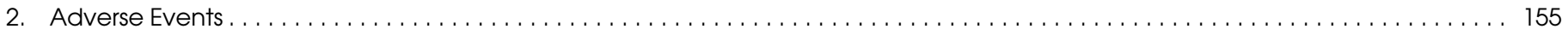

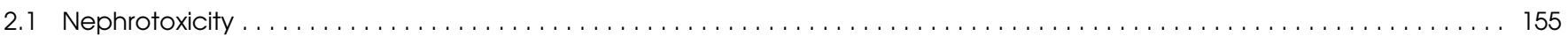

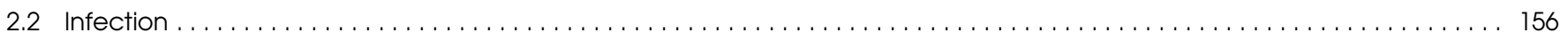

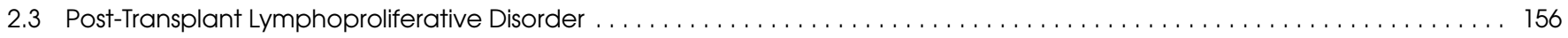

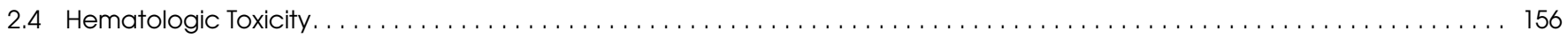

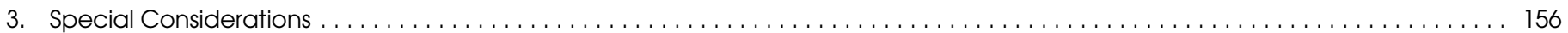

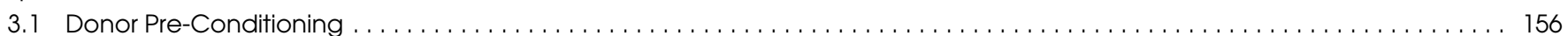

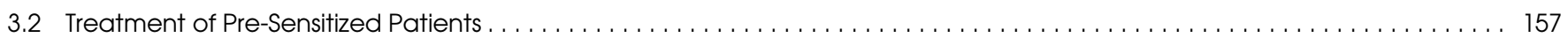

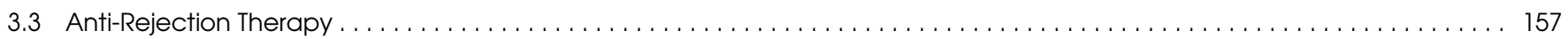

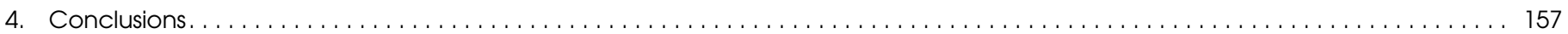

\section{Abstract}

This review summarizes the outcomes and known adverse effects of current immunosuppression strategies in use in pediatric intestinal transplantation. Intestinal transplantation has evolved from an experimental therapy to a highly successful treatment for children with intestinal failure who have complications with total parenteral nutrition. Because of continued success with intestinal transplantation over the past decade, the focus of clinicians and researchers is shifting from short-term patient survival to optimizing long-term outcomes.

Current 5-year patient and graft survival rates after intestinal transplantation are 58\% and $40 \%$, respectively, in the US; single centers have reported nearly $80 \%$ patient and $60 \%$ graft survival rates at 5 years. The immunosuppression strategy in intestinal transplantation includes a tacrolimus-based regimen, usually in conjunction with an antibody induction therapy such as rabbit-antithymocyte globulin, interleukin-2 receptor antagonists, or alemtuzumab. The use of these immunosuppressive regimens, along with improved medical and surgical care, has contributed significantly toward improved outcomes. Optimization of posttransplant immunosuppression strategies to reduce adverse effects while minimizing acute and chronic graft rejection is a strong clinical and research focus. 
For over 2 decades, intestinal transplantation has presented a significant challenge for both clinicians and scientists worldwide because of the difficulty in controlling allograft rejection without imposing a significant risk of infection or drug-related morbidity. After initial case experience with isolated small bowel transplantation, ${ }^{[1-4]}$ tacrolimus was introduced in 1990, allowing more pronounced clinical progress. The initial challenges ${ }^{[5]}$ with intestinal transplantation included technical issues, sepsis, rejection, and development of necessary clinical expertise with immunosuppression for both maintenance therapies as well as for management of rejection episodes. Further technical improvements in both donor intestine recovery and recipient surgery, ${ }^{[6-8]}$ better understanding of infectious complications,${ }^{[9]}$ and novel immunosuppression regimens ${ }^{[10-13]}$ have significantly improved patient and graft survival. Other important achievements that have contributed to decreased mortality have been improved postoperative infectious prophylaxis and serial viral load monitoring with pre-emptive therapy for cytomegalovirus and Epstein-Barr virus infections, with subsequent reduction in the development of posttransplant lymphoproliferative disorders (PTLDs). ${ }^{[14]}$

Despite these advances, areas needing ongoing improvement include reduction of mortality and late graft loss. The Intestinal Transplant Registry (see section 1.1) reports sepsis (54\%), rejection (7\%), and PTLD (3\%) as ongoing causes of death. ${ }^{[15]}$ Although acute cellular rejection has been well managed with current immunosuppression regimens, graft loss due to chronic rejection is a newer concern as longer term survival is being achieved. ${ }^{[16]}$

The objective of this review is to summarize the outcomes and known adverse effects of current immunosuppression strategies in use in pediatric intestinal transplantation. The Intestinal Transplant Registry (ITR; see section 1.1), Organ Procurement and Transplantation Network/Scientific Registry of Transplant Recipients (OPTN/SRTR; section 1.2), and single center reports (section 1.3) were used for compilation of data for this review.

\section{Clinical Experience with Immunosuppressive Regimens}

The first long-term survivor of pediatric intestinal transplantation was maintained under cyclosporine (ciclosporin) immunosuppression by Goulet et $\mathrm{al}^{[2]}$ in 1989, and 22 years later the patient is still alive and well. Tacrolimus subsequently replaced cyclosporine and has become the primary maintenance immunosuppressant agent in pediatric intestinal transplantation.

Recently, induction immunosuppression with antibody preparations such as rabbit antithymocyte globulin [rATG]
(Thymoglobulin ${ }^{\circledR}$; Sangstat, Menlo Park, CA, USA), alemtuzumab (Campath ${ }^{\circledR}$; Genzyme Corporation, Cambridge, MA, USA), basiliximab (Simulect ${ }^{\circledR}$; Novartis Pharmaceuticals, East Hanover, NJ, USA), daclizumab (Zenapax ${ }^{\circledR}$; Hoffmann La Roche, Nutley, NJ, USA), and muromonab CD3 (OKT3, Orthoclone OKT $3{ }^{\circledR}$; Ortho Biotech, Raritan, NJ, USA) have been increasingly employed in intestinal transplantation in an effort to improve clinical outcomes, and patient and graft survival rates. Classification, pertinent mechanism of action, and adverse effects of common immunosuppressant drugs used in pediatric intestinal transplantation are reviewed in detail elsewhere ${ }^{[17-21]}$ and summarized in table I.

\subsection{Intestinal Transplant Registry}

Overall, the $\mathrm{ITR}^{[15]}$ has summarized 25 years of experience with intestinal transplantation from April 1985 through 31 May 2009. The database includes information on 2188 transplants performed on 2038 patients at 73 centers worldwide. These transplants comprised small bowel $(n=926)$, liver-small bowel $(n=725)$, and multivisceral (grafts inclusive of stomach; $n=537$ ). More than half (1238/2038) of the recipients are currently alive.

1236 pediatric intestine transplants were performed in 1151 children aged $<18$ years. 542 of these recipients are currently alive, of whom $464(86 \%)$ are currently off total parenteral nutrition. Over time, pediatric intestine transplants have grown to a current rate of more than 120 transplants per year. Indications for pediatric intestinal transplantation include gastroschisis (24\%), necrotizing enterocolitis (16\%), volvulus (15\%), intestinal atresia (9\%), motility disorders (14\%), mucosal defects (10\%), re-transplantation (5\%), neoplasm (1\%), and others (2\%). The use of pre-transplant immunosuppression with interleukin (IL)-2 receptor antibodies or antilymphocyte products has gradually increased over the past 2 decades. IL-2 receptor antibodies remain the most common pre-transplant immunosuppressant recorded in the registry.

Intestinal transplants continue to have challenging postoperative courses, with a mean hospital stay of 1-2 months. Because the level of immunosuppression required is relatively high compared with other transplants, the reported incidence of PTLD remains approximately $11-14 \%$. Sepsis continues to be the leading cause of death in pediatric intestine transplantation.

\subsection{US Data}

According to the OPTN/SRTR, ${ }^{[22]} 1848$ intestinal transplants were performed in the US between 1 January 1988 and 30 September 2009. 1075 (58\%) of these transplants were carried out in 
Table I. Classification, mechanism of action, and adverse effects of common immunosuppressive drugs used in pediatric intestinal transplantation

\begin{tabular}{lll}
\hline Class/agent & Mechanism of action & Adverse effects \\
\hline Induction therapy &
\end{tabular}

Rabbit antithymocyte globulin

(Thymoglobulin ${ }^{\circledR}$; Sangstat, Menlo Park, CA, USA)

Alemtuzumab (Campath ${ }^{\circledR}$; Genzyme

Corporation, Cambridge, MA, USA)

Daclizumab (Zenapax ${ }^{\circledR}$; Hoffmann La Roche, Nutley, NJ, USA)

Basiliximab (Simulect ${ }^{\circledR}$; Novartis Pharmaceuticals, East Hanover, NJ, USA)

Muromonab CD3 $\left(\mathrm{OKT}_{3}\right.$, Orthoclone $\mathrm{OKT}^{\circledR}{ }^{\circledR}$; Ortho Biotech, Raritan, NJ, USA)

\section{Maintenance therapy}

Tacrolimus (Prograf ${ }^{\circledR}$; Astellas Pharma US, Deerfield, IL, USA)

Sirolimus (Rapamune ${ }^{\circledR}$; Wyeth Pharmaceuticals, Philadelphia, PA, USA)

Azathioprine (Imuran ${ }^{\circledR}$; GlaxoSmithKline, Research Triangle Park, NC, USA)

Mycophenolic acid (CellCept ${ }^{\circledR}$, Hoffmann La Roche, Nutley, NJ, USA; Myfortic ${ }^{\circledR}$, Novartis Pharmaceuticals, East Hanover, NJ, USA)

Prednisone
Polyclonal $\gamma$-globulin against a wide spectrum of T-cell antigens, including CD2, CD3, CD11a, and CD45; inhibits CXCR-4/SDF- $1 \alpha$-mediated chemotaxis; expands $\mathrm{CD}^{+}{ }^{+} \mathrm{CD} 25^{+} \mathrm{Foxp}^{+}$Treg population, which suppress direct alloimmune response

Humanized rat monoclonal antibody against CD52 expressed on lymphocytes, monocytes, macrophages, and eosinophils

Human IgG1 monoclonal antibody, which targets IL-2 $\alpha$-chain or CD25 antigen expressed on activated $T$ cells

Chimeric mouse-human monoclonal antibody, which binds to the $\alpha$-subunit (CD25) of IL-2 receptor

Murine IgG2 antibody, which specifically recognizes the human CD3 molecular complex on the T-cell receptor complex

Binds to an intracellular protein immunophilin; the immunophilin-tacrolimus complex inhibits the phosphatase activity of calcineurin, resulting in inhibition of transcription of cytokines,

particularly IL-2

Binds to intracellular binding protein (FKBP12); sirolimus-FKBP12 complex inhibits the mTOR, resulting in inhibition of tyrosine kinase essential for cytokine driven $\mathrm{T}$-cell activation and proliferation

Purine analog converted to 6-mercaptopurine in vivo; inhibits purine nucleoside synthesis and metabolism required for replication and cellular activation of $B$ and $T$ cells

Selective inhibitor of inosine dehydrogenase, a pre-requisite for the de novo pathway of purine synthesis on which $B$ and $T$ cells are dependent for replication and cellular activation

Inhibition of IL-1 and -2; reduction in proliferation of helper T cells, suppressor T cells, cytotoxic T cells, and B cells; suppression of antibody production; reduction in migration and activity of neutrophils
Cytokine release syndrome (infusion-related reactions, including fever, rash, hypotension, hypertension, headache, nausea, dyspnea), myelosuppression (thrombocytopenia, neutropenia), opportunistic infections, PTLD

Cytokine release syndrome, myelosuppression (pancytopenia, anemia, thrombocytopenia), opportunistic infections, PTLD

Uncommon; allergic reactions, including anaphylaxis

Uncommon; allergic reactions, including anaphylaxis

Severe cytokine release syndrome, opportunistic infections, PTLD

Nephrotoxicity, neurotoxicity, hypertension, diabetes mellitus, cholestatic syndrome, gastrointestinal side effects, PTLD

Impaired wound healing, dyslipidemias, proteinuria, peripheral edema and dermatitis, mouth ulcers, arthralgias, diarrhea, elevated liver enzyme levels, decreased renal function, interstitial pneumonia

Myelosuppression, hepatic nodular hyperplasia and portal sclerosis, atypical infections, gastrointestinal upset, rashes, hypersensitivity reactions

Myelosuppression, severe gastrointestinal disturbances (common), opportunistic

infections, PTLD

Hypertension, diabetes mellitus, dyslipidemias, $\quad 17,18$ osteopenia, osteoporosis, cataracts, growth retardation

of


Recent developments in immunosuppressive regimens in the US from 1999 to 2008 have been tabulated in the 2009 OPTN/ Scientific Registry of Transplant Recipients (SRTR) annual report ${ }^{[22]}$ and were summarized by Mazariegos et al. ${ }^{[23]}$ Over the past decade, newer trends in immunosuppression have been seen and immunosuppressive regimens continue to evolve. Along with single-center reports of successful experience with $\mathrm{rATG}^{[19]}$ and alemtuzumab, ${ }^{[24,25]}$ the 2009 OPTN/SRTR annual report also documents increasing use of induction therapy with antibody preparations. ${ }^{[22]}$ For example, the most common induction regimen ${ }^{[22]}$ in 2008 was rATG, which was used in $34 \%$ of intestine recipients, followed by alemtuzumab (18\%), muromonab CD3 (15\%), and daclizumab (8\%). The use of induction immunosuppression peaked in 2003 and stabilized to its current use in $60 \%$ of transplant recipients in $2008 .{ }^{[23]}$ The immunosuppression regimen used for maintenance therapy prior to hospital discharge ${ }^{[22]}$ in 2008 (figure 1) included tacrolimus plus corticosteroids in 55\% of intestinal transplant recipients, tacrolimus plus mycophenolate and corticosteroids in 13\%, tacrolimus plus mycophenolate in $11 \%$, and tacrolimus alone in $11 \%$; the maintenance regimen at 1-year post-transplant ${ }^{[22]}$ for transplants carried out in 2007 (figure 2) was tacrolimus and corticosteroids in $47 \%$ of recipients and tacrolimus alone in $33 \%$.

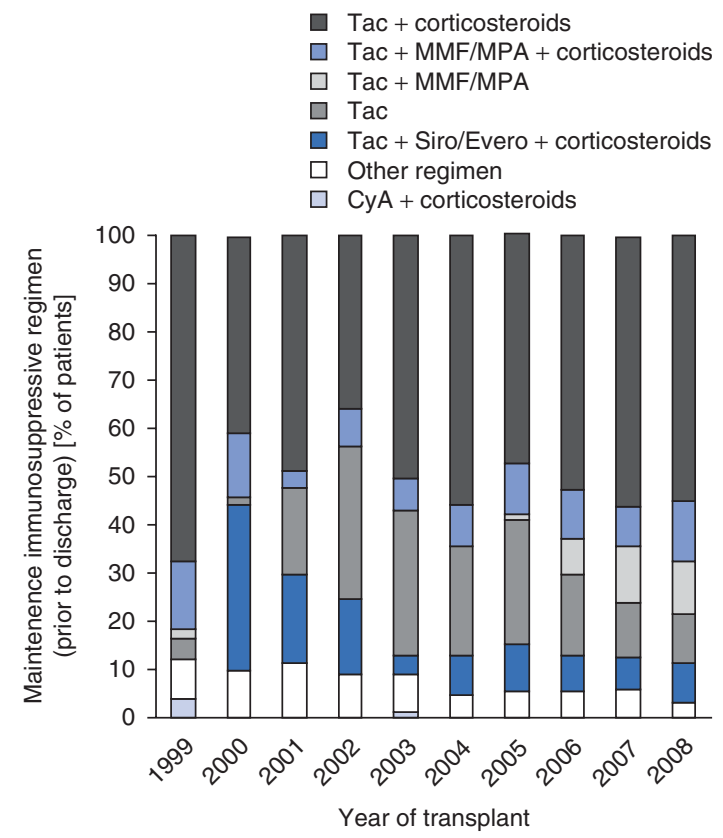

Fig. 1. Immunosuppression use for maintenance therapy by regimen prior to discharge, 1999-2008, using data from the 2009 Organ Procurement and Transplantation Network/Scientific Registry of Transplant Recipients annual report. ${ }^{[22]}$ CyA=cyclosporine (ciclosporin); Evero=everolimus; $\mathbf{M M F}=$ mycophenolate mofetil; MPA=mycophenolate sodium; Siro=sirolimus; Tac $=$ tacrolimus. Other regimen includes drug combinations that are different from the listed regimens.

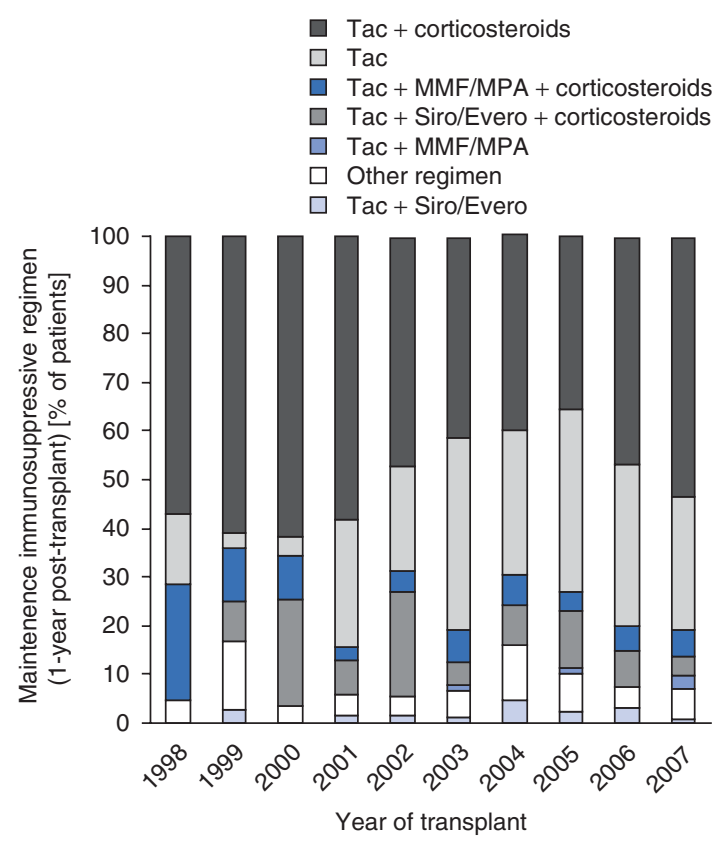

Fig. 2. Immunosuppression use for maintenance therapy by regimen 1 year following transplantation, 1998-2007, using data from the 2009 Organ Procurement and Transplantation Network/Scientific Registry of Transplant Recipients annual report. ${ }^{\text {22] }}$ Evero=everolimus; $\mathbf{M M F}=$ mycophenolate mofetil; $\mathbf{M P A}=$ mycophenolate sodium; Siro=sirolimus; $\mathbf{T a c}=$ tacrolimus. Other regimen includes drug combinations that are different from the listed regimens.

Fifty-seven of 198 (28.8\%) patients received anti-rejection treatment 1-year post-transplantation in 2008. ${ }^{[22]}$ Corticosteroids were used in the treatment of the majority $(83 \%)$ of acute rejection episodes in 2008. ${ }^{[23]}$ The use of antibodies for the treatment of corticosteroid-resistant rejection ${ }^{[22]}$ in 2008 (figure 3) most commonly consisted of muromonab CD3 (53\%), followed by rATG (12\%) and alemtuzumab (12\%).

OPTN/SRTR patient and graft survival rates are shown in figures 4 and 5. Among the recipients of intestine grafts, the unadjusted 1-, 3-, 5-, and 10-year patient and graft survival rates were $89 \%$ and $79 \%, 72 \%$ and $59 \%, 58 \%$ and $40 \%$, and $46 \%$ and $29 \%$, respectively. Among recipients of combined liverintestine grafts, unadjusted 1-, 3-, 5- and 10-year patient and graft survival rates were $63 \%$ and $59 \%, 58 \%$ and $55 \%, 58 \%$ and $53 \%$, and $39 \%$ and $37 \%$, respectively.

\subsection{Single-Center Experience}

In addition to the aggregate data of the Intestinal Transplant Registry (see section 1.1) and the SRTR (see section 1.2), singlecenter data have provided valuable information on long-term outcomes and center experience with the specific regimens. These data are summarized in table II. 


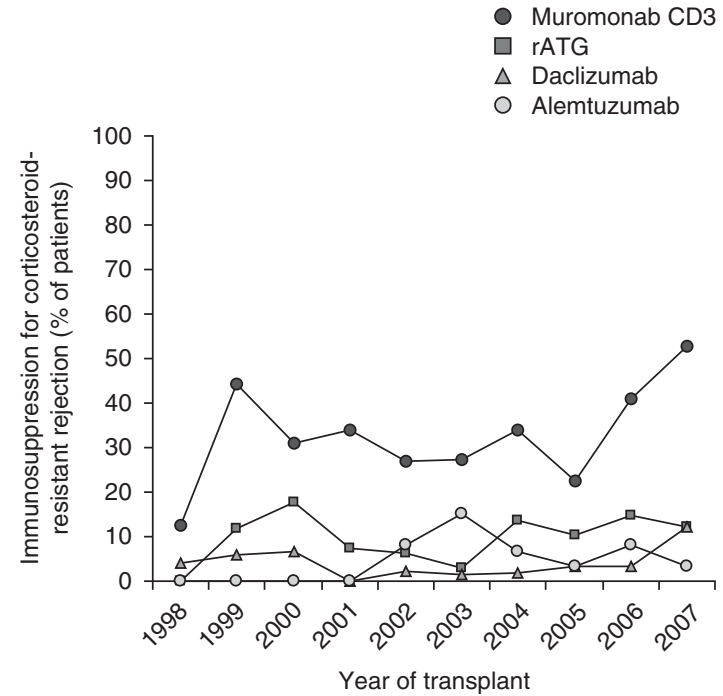

Fig. 3. Immunosuppression use for corticosteroid-resistant rejection from transplant to 1 year following transplantation, 1998-2007, using data from the 2009 Organ Procurement and Transplantation Network/Scientific Registry of Transplant Recipients annual report. ${ }^{[22]}$ rATG=rabbit-antithymocyte globulin.

The current immunosuppressive protocol in place for intestinal transplantation at the Children's Hospital of Pittsburgh of University of Pittsburgh Medical Center (CHP of UPMC) [Pittsburgh, PA, USA] includes induction with rATG followed by maintenance immunosuppression with tacrolimus and low dose corticosteroids. Lymphocyte ablation achieved with T-cell-depleting antibodies combined with minimization of post-transplant immunosuppression was introduced in 2001 and has significantly reduced rejection rates, lowered levels of immunosuppression, and advanced early and intermediateterm graft and patient survival in intestinal transplantation recipients. ${ }^{[26,31-34]} \mathrm{T}$-cell-depleting antibodies primarily include rATG (Thymoglobulin ${ }^{\circledR}$; Sangstat, Menlo Park, CA, USA) at a dose of $5 \mathrm{mg} / \mathrm{kg}$, with alemtuzumab (Campath ${ }^{\circledR}$; Genzyme Corporation, Cambridge, MA, USA) at a dose of $0.4 \mathrm{mg} / \mathrm{kg}$ (maximum of $30 \mathrm{mg}$ ) reserved for use in the sensitized patient or retransplantation. Results from the use of these agents have been promising - the rates of long-term patient and graft survival have significantly increased. ${ }^{[26-30]}$

At CHP, 213 children received 235 intestine-containing allografts between May 1990 and December 2009. Mean age at transplantation was $5.1 \pm 5.3$ years and mean follow-up time was $58.9 \pm 53.4$ months. The incidence of acute rejection posttransplantation was $79 \%$ in the cyclophosphamide plus daclizumab cohort $(\mathrm{n}=39)$, and has decreased to $68 \%$ in the $\mathrm{rATG}$ $(n=104)$ cohort and $36 \%$ in the alemtuzumab $(n=20)$ cohort, compared with $82 \%$ in the cohort in which no induction agent $(\mathrm{n}=50)$ was used. Twenty-eight of the $213(13 \%)$ subjects developed evidence of chronic rejection. The frequency of opportunistic infections and PTLD has also decreased over time. The incidence of tissue infection with cytomegalovirus was $26 \%$ in the cyclophosphamide plus daclizumab cohort, decreasing to $13 \%$ in the rATG plus alemtuzumab cohort. PTLD associated with Epstein-Barr virus infection also decreased from $23 \%$ in the cyclophosphamide plus daclizumab cohort to $11 \%$ in $\mathrm{rATG}$ cohort. This reduction is a coalescence of many contributing factors, such as improved postoperative infection prophylaxis, serial monitoring of cytomegalovirus and Epstein-Barr virus viral loads, pre-emptive therapy with antiviral drugs, and reduction in immunosuppression when titers are elevated.

The overall patient and graft survival rates at CHP were $85 \%$ and $79 \%$, respectively, at 1 year, $73 \%$ and $66 \%$ at 3 years, and $68 \%$ and $55 \%$ at 5 years after transplantation. The patient and graft survival rates in the current rATG plus alemtuzumab cohort (figure 6, table II) were $93 \%$ and $88 \%$, respectively, at 1 year, $85 \%$ and $74 \%$ at 3 years, and $78 \%$ and $59 \%$ at 5 years after transplantation. The patient survival rate did not differ significantly by organ type $(p=0.50)$. The graft survival rates by organ type in the rATG plus alemtuzumab cohort were small bowel (48\%), liver-small bowel (67\%), and multivisceral (58\%) at 5 years after transplantation; these differences were also not significant $(\mathrm{p}=0.08)$.

The University of Miami (Miami, FL, USA) ${ }^{[27]}$ has reported their experience with the induction agents daclizumab and alemtuzumab. The factors associated with favorable survival were the use of induction with daclizumab, a multivisceral allograft with or without liver, the patient at home prior to transplant, and 1 year of age at transplant. Patients who received a

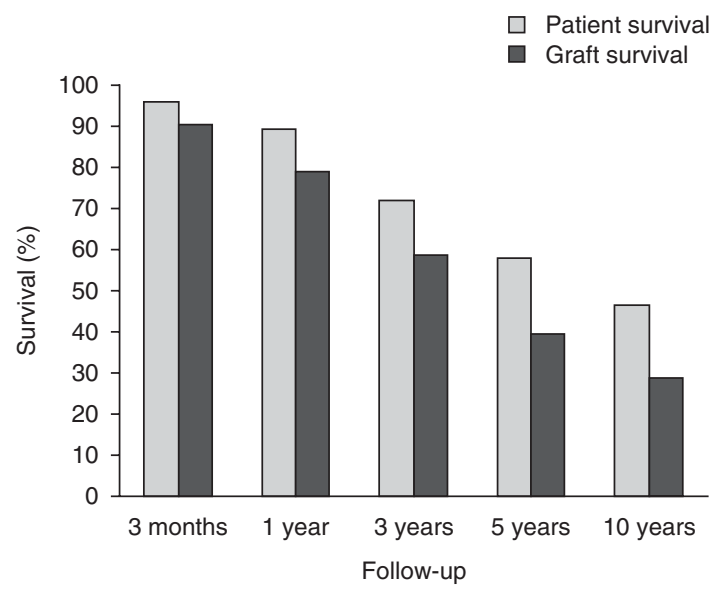

Fig. 4. Unadjusted patient and graft survival for intestine-alone recipients, using data from the 2009 Organ Procurement and Transplantation Network/Scientific Registry of Transplant Recipients annual report. ${ }^{\text {[22] }}$ 


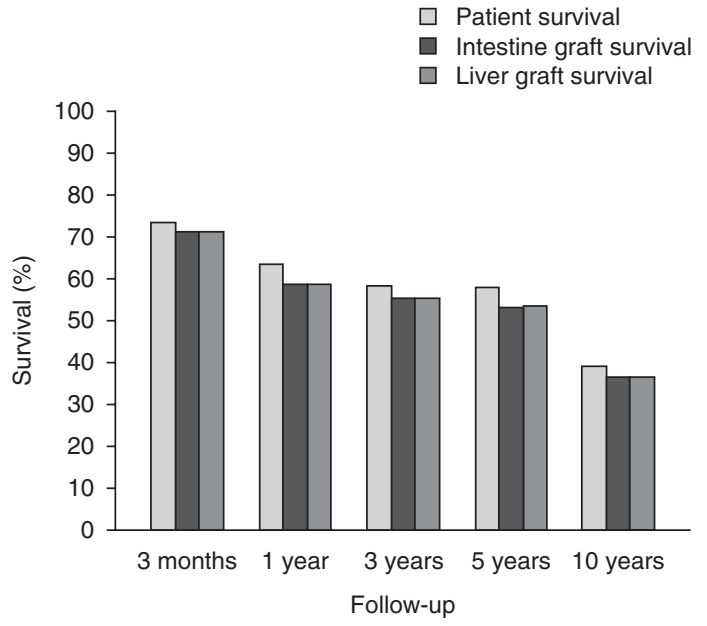

Fig. 5. Unadjusted patient and graft survival for liver-intestine recipients using data from the 2009 Organ Procurement and Transplantation Network/Scientific Registry of Transplant Recipients annual report. ${ }^{[22]}$

multivisceral transplant had a lower mortality rate due to rejection, while older patients were associated with a lower risk of mortality following respiratory infections. Because of irreversible acute respiratory distress syndrome (ARDS)-like illness in three children induced with alemtuzumab, its use at their center since 2002 has been restricted to children 4 years of age and older.
Fishbein et al. ${ }^{[29,30]}$ reported a decline in the incidence of early rejection in intestinal transplant recipients from $70 \%$ to $34 \%$ after the addition of sirolimus to their immunosuppressive regimen, consisting of the IL-2 receptor inhibitor, tacrolimus, and corticosteroids. There was also a significant increase (from $50 \%$ to $88 \%$ ) in the 3 -year actuarial graft survival rate with the use of sirolimus (table II). In subsequent reports, ${ }^{[29]}$ sirolimus has been associated with anemia and wound dehiscence, and its role as a short-term adjunct to early tacrolimus immunosupression after intestinal transplantation or as a maintenance immunosuppressant agent remains to be defined.

Goulet et al. ${ }^{[28]}$ described their experience with the induction agent basiliximab (Novartis, Basel, Switzerland) followed by maintenance immunosuppression with tacrolimus and corticosteroids. The overall 1- and 3-year graft survival rates were $58 \%$ and $52.5 \%$, respectively; however, the graft survival for liver-small bowel allograft was significantly higher than for isolated small bowel allograft (table II). The rates of EpsteinBarr virus-related PTLD and cytomegalovirus disease were $15 \%$ and $19 \%$, respectively, at their center. The important conclusions from this study included improved graft survival with the use of IL-2 receptor antibodies for induction as compared to those induced with tacrolimus and methylpredniso-

Table II. Single-center reports and outcomes after the use of various immunosuppressive regimens for pediatric intestinal transplantation

\begin{tabular}{|c|c|c|c|c|}
\hline Study $(y)$, center & $\begin{array}{l}\text { No. of } \\
\text { patients }\end{array}$ & $\begin{array}{l}\text { Induction } \\
\text { immunosuppression }\end{array}$ & Maintenance immunosuppression & $\begin{array}{l}\text { 1-, 3- and 5-year } \\
\text { patient and graft } \\
\text { survival (\%) }\end{array}$ \\
\hline $\begin{array}{l}\text { Nayyar et al. (2011; present review) [figure 6], Children's } \\
\text { Hospital of Pittsburgh of University of Pittsburgh Medical } \\
\text { Center, Pittsburgh, PA, USA }\end{array}$ & 124 & $\begin{array}{l}\text { Rabbit antithymocyte } \\
\text { globulin or alemtuzumab }\end{array}$ & Tacrolimus + corticosteroids & $\begin{array}{l}93 / 88,85 / 74 \\
78 / 59\end{array}$ \\
\hline Bond et al. ${ }^{[26]}$ (2005), University of Pittsburgh, PA, USA & 48 & $\begin{array}{l}\text { No induction } \\
\text { Cyclophosphamide or } \\
\text { daclizumab or rabbit } \\
\text { antithymocyte globulin }\end{array}$ & $\begin{array}{l}\text { Tacrolimus + corticosteroids } \\
\text { Tacrolimus + corticosteroids }\end{array}$ & $\begin{array}{l}81 / 76,62 / 60 \\
61 / 51^{\mathrm{a}}\end{array}$ \\
\hline Kato et al. ${ }^{[27]}$ (2006), University of Miami, FL, USA. & $\begin{array}{l}51 \\
18\end{array}$ & $\begin{array}{l}\text { Daclizumab } \\
\text { Alemtuzumab }\end{array}$ & $\begin{array}{l}\text { Tacrolimus }+ \text { corticosteroids } \\
\text { Tacrolimus }+ \text { corticosteroids }\end{array}$ & $\begin{array}{l}83 /-, 60 /-,-/- \\
44 /-, 44 /-,-/-\end{array}$ \\
\hline $\begin{array}{l}\text { Goulet et al. }{ }^{[28]}(2005) \text {, Necker-Enfants Malades, } \\
\text { Paris, France. }\end{array}$ & $\begin{array}{l}24 \\
28\end{array}$ & $\begin{array}{l}\text { No induction } \\
\text { Basiliximab }\end{array}$ & $\begin{array}{l}\text { Tacrolimus }+ \text { corticosteroids } \\
\text { Tacrolimus }+ \text { corticosteroids }\end{array}$ & $-/ 54,-/ 43,-/-^{b}$ \\
\hline \multirow[t]{2}{*}{$\begin{array}{l}\text { Fishbein et al. }{ }^{[29]} \text { (2002), Mount Sinai School of } \\
\text { Medicine, New York, NY, USA. }\end{array}$} & 17 & $\begin{array}{l}\text { Daclizumab or } \\
\text { muromonab CD3 }\end{array}$ & Tacrolimus + corticosteroids & $79 / 58,-/-,-/-$ \\
\hline & 12 & Basiliximab & Tacrolimus + sirolimus + corticosteroids & $92 / 92,-/,-/-$ \\
\hline \multirow[t]{2}{*}{$\begin{array}{l}\text { Fishbein et al.[}{ }^{[30]} \text { (2003), Georgetown University, } \\
\text { Washington DC, USA. }\end{array}$} & 8 & $\begin{array}{l}\text { Daclizumab or } \\
\text { muromonab }\end{array}$ & Tacrolimus + corticosteroids & $-/-, 88 / 50,-/-$ \\
\hline & 18 & Basiliximab & Tacrolimus + sirolimus + steroids & $-/-, 90 / 88,-/-$ \\
\hline
\end{tabular}

a These figures refer to the total patient population (i.e. no induction plus induction).

b These figures refer to the isolated small bowel cohort irrespective of whether they received induction therapy or not.

- indicates no data. 


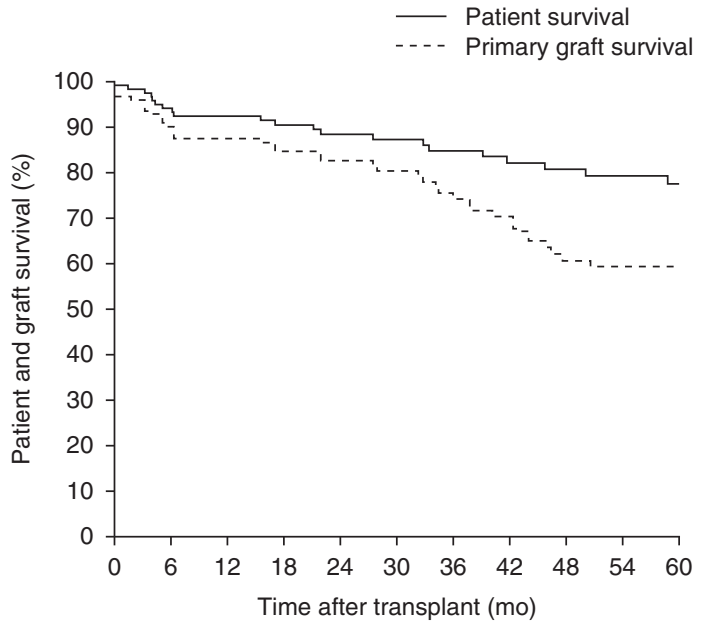

Fig. 6. Patient and primary graft survival in the cohort of patients induced with rabbit antithymocyte globulin plus alemtuzumab at the Children's Hospital of Pittsburgh $(n=124)$.

lone alone; lower incidence and severity of acute rejection in recipients of liver-small bowel transplantation; no effect on survival after inclusion of the colon as a part of the allograft; and longer time required to achieve full enteral nutrition after combined liver-small bowel transplantation.

The Leuven multi-step protoco ${ }^{[35]}$ was designed to enhance the generation of regulatory $\mathrm{T}$ cells that are hypothesized to play a major role in protection from rejection. The protocol involves donor and recipient intestine decontamination to prevent endotoxin translocation; protection of the mucosal intestinal barrier in both donors and recipients by administration of glutamine; a donor-specific blood transfusion at the time of transplantation to promote development of regulatory cells; induction with either IL-2 receptor antagonists or rATG; and maintenance immunosuppression with low-dose tacrolimus, azathioprine, and corticosteroids. Only seven patients have been treated with the Leuven pro-regulatory regimen and additional experience is required to evaluate the merits of the treatment.

\section{Adverse Events}

The improved efficacy achieved with tacrolimus-based regimens has led to a large cohort of surviving intestine transplant recipients. As a result, a growing population is being managed with long-term immunosuppression after intestinal transplantation. Minimizing the adverse effects of conventional immunosuppression, such as opportunistic infection, malignancy, and growth retardation, is of vital importance in this challenging pediatric population. Adverse effects of common immunosuppressant drugs used in pediatric intestinal transplantation are summarized in table I.
Current immunosuppressive strategies are aimed at reducing these adverse effects by evolving regimens that incorporate drug monitoring, combining different types of drugs in a novel way such that they complement each other, replacing one drug with another one exhibiting a different toxicity profile, and tailoring the immunosuppression according to appropriate clinical requirements. ${ }^{[17]}$

Lifelong therapeutic monitoring of tacrolimus blood concentrations is required to regulate drug levels and dosage in order to avoid suboptimal concentrations leading to graft rejection, or toxic levels potentially leading to adverse effects, including Epstein-Barr virus-related PTLD and nephrotoxicity. Also, in patients with refractory rejection despite optimal intensification of immunosuppression, the risk of over-immunosuppression, including opportunistic infections and malignancies, have to be balanced with the consequences of graft loss due to rejection. In some instances, enterectomy and re-transplantation ${ }^{[36]}$ may be preferable to severe infectious or malignant adverse effects.

\subsection{Nephrotoxicity}

Chronic renal failure is one of the leading causes of posttransplant morbidity and mortality after intestinal transplantation. Ojo et al. ${ }^{[37]}$ conducted a population-based cohort analysis involving recipients of solid organ transplants using the SRTR database to evaluate the incidence of chronic renal failure, defined as glomerular filtration rate (GFR) $<29 \mathrm{~mL} / \mathrm{min} / 1.73 \mathrm{~m}^{2}$ or end-stage renal disease. Chronic renal failure was associated with a 4-fold increased risk of death after transplantation, and 5 -year survivors of intestinal transplantation had a $21 \%$ incidence of chronic renal failure, which is the highest incidence rate among non-renal transplant recipients.

Ueno et al. ${ }^{[38]}$ assessed renal function after pediatric intestinal transplantation and found that calculated GFR dropped significantly to $81 \%$ of the pre-transplantation value from 138 to $102 \mathrm{~mL} / \mathrm{min} / 1.73 \mathrm{~m}^{2}$, and elevated tacrolimus levels predicted the subsequent development of renal impairment at 2 years after pediatric intestinal transplantation. The same group also reported that the mean creatinine clearance decreased from a pre-transplant value of $114 \mathrm{~mL} / \mathrm{min} / 1.73 \mathrm{~m}^{2}$ to $49.6 \mathrm{~mL} / \mathrm{min} / 1.73 \mathrm{~m}^{2}$, and also found a significant association between cumulative tacrolimus levels $>4500 \mathrm{ng} \bullet$ day $/ \mathrm{mL}$ and a decreased creatinine clearance at 2 years after adult intestinal transplantation. ${ }^{[39]}$

The optimal treatment strategy for pediatric intestinal transplantation recipients with calcineurin toxicity is unknown, but should include consideration of mycophenolate mofetil, sirolimus, or azathioprine. 


\subsection{Infection}

Sepsis is the leading cause of mortality after intestinal transplantation. Unique challenges ${ }^{[9]}$ in this patient population include increased frequency of blood stream infections with enteric pathogens due to translocation from intestinal pathology, and relatively higher levels of required maintenance immunosuppression. Bacterial, fungal, and viral infections are common $^{[27,33]}$ and require a high index of suspicion and early intervention with appropriate antibiotics or antiviral therapy, and investigation for gastrointestinal pathology. Since children are more likely to be seronegative for cytomegalovirus and Epstein-Barr virus, routine Epstein-Barr virus polymerase chain reaction surveillance in blood is recommended to ensure early detection, treatment, and monitoring of infection.

\subsection{Post-Transplant Lymphoproliferative Disorder}

The use of intense immunosuppression has led to a high incidence of PTLD, with the highest rates reported among solid-organ recipients. As a result of the use of optimal maintenance immunosuppression, and careful monitoring and preemptive treatment for Epstein-Barr virus, the current incidence of PTLD is decreasing. Abu-Elmagd et al. ${ }^{[40]}$ recently reported that de novo malignancy developed in $15 \%$ of patients, with a median diagnosis time of 5.5 months (range 1-116 months) after visceral transplantation, with PTLD occurring in 13\% and non-lymphoid cancer in $3.2 \%$. Children had a significantly higher risk of developing PTLD (37 of 52 [71\%]), and adults were more vulnerable to non-lymphoid cancer (10 of 13 [77\%]). PTLD occurred within the first postoperative year in $71 \%$ of patients, and the intestinal allograft was the primary site in $71 \%$ of recipients. Reyes et al. ${ }^{[41]}$ have shown that the odds ratio for the development of PTLD decreased to 0.39 , and death or graft loss due to PTLD decreased to 0.36 following the implementation of aggressive monitoring and pre-emptive treatment of Epstein-Barr virus. Other treatment modalities for advanced PTLD include the use of rituximab and chemotherapy.

\subsection{Hematologic Toxicity}

Clinicians should be aware of the risks and presentations of cytopenias, thrombotic microangiopathy, and hemolytic uremic syndrome in pediatric intestinal transplantation patients. A subset of intestinal transplantation patients may be prone to developing immune dysregulations, which can range from asymptomatic auto-antibodies to hematologic abnormalities.

Botija and colleagues ${ }^{[42]}$ observed autoimmune cytopenia in 6 of $49(12.2 \%)$ patients at the median time of 10 months after intestinal transplantation. Warm autoimmune-type hemolytic anemia developed in three patients, cold autoimmune-type hemolytic anemia developed in one patient, and two patients presented with a mixed type of hemolytic anemia. All patients were successfully treated with high-dose corticosteroids, intravenous immunoglobulin, and plasmapheresis. Tacrolimus was switched to sirolimus in four of six $(66 \%)$ patients. The authors concluded that the immunosuppressant drugs used, associated Epstein-Barr virus infection, PTLD, graft-versushost disease, and the inclusion of the spleen as part of the multivisceral graft are important risk factors for the development of autoimmune cytopenia.

Lacaille et al. ${ }^{[43]}$ reported severe and potentially life-threatening dysimmune anemia and thrombocytopenia in six children after liver or small bowel transplantation, which was successfully treated with corticosteroids in three children, and rituximab in the other three. All children were on tacrolimus and low-dose alternate-day corticosteroids when dysimmune cytopenia developed. Dierickx et al. ${ }^{[44]}$ reported three cases of intestinal transplantation-associated thrombotic microangiopathy, which was treated with tacrolimus withdrawal and plasmapheresis. Two of three patients were also receiving maintenance immunosuppression with sirolimus and corticosteroids. Paramesh et al. ${ }^{[45]}$ reported two cases of thrombotic microangiopathy associated with combined sirolimus and tacrolimus immunosuppression after intestinal transplantation. One patient was treated with plasma exchange transfusions, reduction of tacrolimus dosage, and cessation of sirolimus, while the other was treated with plasma exchange transfusions, and replacement of tacrolimus and sirolimus with ciclosporin and mycophenolate mofetil, respectively. Humar et al. ${ }^{[46]}$ reported two cases of hemolytic uremic syndrome after intestinal transplantation. One patient presented with renal failure; immunosuppression was changed from tacrolimus to ciclosporin, but renal function did not improve. A second patient presented with ischemic ulcers in the bowel mucosa secondary to occlusive thrombi in the allograft microcirculation, which was successfully managed by reducing the tacrolimus dose.

\section{Special Considerations}

\subsection{Donor Pre-Conditioning}

Donor pre-conditioning with muromonab CD3 (Don Mills, Toronto, ON, Canada), Minnesota antilymphocyte globulin, and methylprednisolone were used in the first successful liverintestinal transplantation procedure in 1988 by Grant et al. ${ }^{[3]}$ Other centers have used a combination of horse antithymocyte 
globulin (Fresenius, Munich, Germany), with or without murine anti-T-cell monoclonal antibody muromonab CD3 (Raritan, NJ, USA, and Novartis, Basel, Switzerland) for donor preconditioning. ${ }^{[47]}$ A preliminary experimental study by Fryer et al. ${ }^{[48]}$ in a rat model suggested that donor pre-treatment has the potential to reduce the incidence of acute cellular rejection by reducing the donor antigen load that is presented to the host. A significantly milder rejection with less arteritis and prolonged graft survival was seen in the allografts of the recipient macrophage-depleted group compared with non-depleted controls.

\subsection{Treatment of Pre-Sensitized Patients}

The first report to address the impact of a positive T-cell lymphocytotoxic crossmatch on intestinal allograft rejection and survival ${ }^{[49]}$ found that $18 \%$ of intestinal recipients were harboring preformed anti-donor IgG lymphocytotoxic antibodies. Positive T-cell lymphocytotoxic crossmatch increased the frequency and severity of rejection after isolated intestinal transplantation. In our analysis of 103 consecutive primary small bowel transplantation recipients, $18 \%$ of recipients with a positive T-cell crossmatch and $21 \%$ of small-bowel transplantation recipients with complement-dependent cytotoxicity-anti-HLA panel reactive antibody (CDC-PRA) titers of $>15 \%$ experienced graft loss. ${ }^{[50]}$

In an effort to improve post-transplant outcomes after intestinal transplantation, an intravenous immunoglobulinbased immunomodulation protocol for sensitized small bowel transplant candidates was studied by Gondolesi et al. ${ }^{[51]} \mathrm{A}$ stepwise protocol included level 1 treatment with intravenous immunoglobulin $200 \mathrm{mg} / \mathrm{kg}$ every other week for a total of two doses, level 2 treatment with intravenous immunoglobulin $500 \mathrm{mg} / \mathrm{kg}$ every other week for a total of two doses, level 3 treatment with intravenous immunoglobulin $1000 \mathrm{mg} / \mathrm{kg}$ with plasmapheresis three times per week if two venous access sites were available, otherwise mycophenolate mofetil (1 $\mathrm{g}$ twice daily), and level 4 treatment with rituximab $375 \mathrm{mg} / \mathrm{m}^{2}$ every other week for a total of four doses, with escalation to the next level of treatment if there was no significant decrease in PRA titers with the previous treatment. The transplant was performed regardless of the PRA titer if the crossmatch was negative. All transplanted patients responded to level 2 of therapy, and the mean pretreatment PRA titer in transplanted patients decreased from $66.2 \%$ to $25.5 \%$ at the end of treatment. Only one of six patients required level 4 treatment. This patient's PRA titers remained $>90 \%$, representing treatment failure. The authors concluded that intravenous immunoglobulin treatment can desensitize patients on a waiting list, as evidenced by a decrease in PRA titers, resulting in excellent post-transplant outcomes. Although there was no significant decrease in the incidence of acute rejection between the two cohorts with low and high PRA, there was a significant decrease in the incidence of corticosteroid-resistant rejections.

Another potential innovative treatment is the use of the proteosomal inhibitor bortezomib (Velcade ${ }^{\circledR}$; Millennium Pharmaceuticals, Cambridge, MA, USA), which could also provide a new option for desensitization of patients with a high level of donor-specific antibodies. ${ }^{[52]}$ The efficacy of bortezomib as a part of desensitization protocols will require further study.

\subsection{Anti-Rejection Therapy}

Rejection remains common after intestine transplantation. ${ }^{[53,54]}$ Rejection episodes are treated with a $30 \mathrm{mg} / \mathrm{kg}$ dose of methylprednisolone given intravenously in three divided doses over 3 days, or as a $10 \mathrm{mg} / \mathrm{kg}$ bolus on day 1 followed by tapering doses of 5, 4, 3, and $2 \mathrm{mg} / \mathrm{kg}$ on days $2,3,4$ and 5, respectively. Corticosteroid-resistant rejection is typically treated with rATG (Thymoglobulin ${ }^{\circledR}$; Sangstat, Menlo Park, CA, USA) after premedication with methylprednisolone, diphenhydramine, and acetaminophen (paracetamol) to attenuate tumor necrosis factor- $\alpha$ - and IL-1-mediated cytokine release syndrome.

\section{Conclusions}

As a result of continued efforts spanning 2 decades, the 10year patient survival for intestine-only recipients $(46 \%)$ is greater than that for heart-lung recipients (29\%) and lung-only recipients $(28.6 \%)$ but lags behind that for other solid organ transplants (2009 OPTN/SRTR annual report). ${ }^{[22]}$

At experienced centers, 5-year patient and graft survival rates approach $80 \%$ and $60 \%$, respectively. The use of induction immunosuppression is associated with better long-term patient survival; however, achieving improved long-term ( $>10$ year) graft survival remains a clinical priority.

Further research and development to improve the efficacy and tolerability of existing immunosuppressant drugs and protocols in children with an emphasis on the avoidance of long-term adverse events and long-term maintenance of graft function will challenge the transplant community and provide our patients with sustained benefits after intestinal transplantation.

\section{Acknowledgments}

The authors would like to acknowledge the work of Dale Zecca (Administrative Assistant) and Christine Heiner (Scientific Writer in the 
Department of Surgery, Children's Hospital of Pittsburgh of UPMC) in the review and preparation of this manuscript. No sources of funding were used to prepare this manuscript. The authors have no conflicts of interest to declare that are directly relevant to the content of this review.

\section{References}

1. Deltz E, Schroeder P, Gebhardt H, et al. Successful clinical small bowel transplantation: report of a case. Clin Transplant 1989; 3: 89-91

2. Goulet $\mathrm{O}$, Revillon $\mathrm{Y}$, Jan D, et al. Small-bowel transplantation in children. Transplant Proc 1990; 22: 2499-500

3. Grant D, Wall W, Mimeault R, et al. Successful small-bowel/liver transplantation. Lancet 1990; 335: 181-4

4. Starzl TE, Todo S, Tzakis A, et al. The many faces of multivisceral transplantation [published erratum appears in Surg Gynecol Obstet 1991 Sep; 173 (3): 242]. Surg Gynecol Obstet 1991 May; 172 (5): 335-44

5. Todo $\mathrm{S}$, Reyes J, Furukawa $\mathrm{H}$, et al. Outcome analysis of 71 clinical intestinal transplantations. Ann Surg 1995 Sep; 222 (3): 270-80; discussion 280-2

6. DeVille D, Goyet J, Mitchell A, et al. En block combined reduced liver and small bowel transplants: from large donors to small children. Transplantation 2000; 69: 555-9

7. Bueno J, Abu-Elmagd K, Mazariegos G, et al. Composite liver-small bowel allografts with preservation of donor duodenum and hepatic biliary system in children. J Pediatr Surg 2000; 35: 291-5

8. Abu-Elmagd K, Fung J, Bueno J, et al. Logistics and technique for procurement of intestinal, pancreatic, and hepatic grafts from the same donor. Ann Surg 2000; 232 (5): 680-7

9. Green M, Bueno J, Sigurdsson L, et al. Unique aspects of the infectious complications of intestinal transplantation. Curr Opin Organ Transpl 1999; 4: $361-7$

10. Abu-Elmagd K, Reyes J, Bond G, et al. Clinical intestinal transplantation: a decade of experience at a single center. Ann Surg 2001; 234 (4): 404-17

11. Reyes J, Mazariegos G, Bond G, et al. History of pediatric organ transplantation: pediatric intestinal transplantation: historical notes, principles and controversies. Pediatr Transplant 2002 Jun; 6 (3): 193-207

12. Abu-Elmagd K, Reyes J, Todo S, et al. Clinical intestinal transplantation: new perspectives and immunologic considerations. J Am Coll Surg 1998; 186 (5): 512-27

13. Pinna AD, Weppler D, Nery JR, et al. Induction therapy for clinical intestinal transplantation: comparison of four different regimens. Transplant Proc 2000 Sep; 32 (6): 1193-4

14. Pineda J, Mazariegos GV. Post-transplantation lymphoproliferative disorder (PTLD) in liver and small bowel transplant recipients. In: Dharnidharka VR, Green M, Webber SA, editors. Post-transplantation lymphoproliferative disorders. Berlin, Heidelberg: Springer-Varlag, 2010: 153-62

15. Intestinal Transplant Association (ITA) [online]. Available from URL: http:// www.intestinaltransplant.org [Accessed $2011 \mathrm{Feb}$ 15]

16. Parizhskaya M, Redondo C, Demetris A, et al. Chronic rejection of small bowel grafts: a pediatric and adult study on risk factors and morphologic progression. Pediatr Dev Pathol 2003; 6 (3): 240-50

17. Al-Hussaini A, Tredger JM, Dhawan A. Immunosuppression in pediatric liver and intestinal transplantation: a closer look at the arsenal. J Pediatr Gastroenterol Nutr 2005; 41: 152-65

18. Tredger JM, Brown NW, Dhawan A. Immunosuppression in pediatric solid organ transplantation: opportunities, risks, and management. Pediatr Transplantation 2006; 10: 879-92

19. Reyes J, Mazariegos GV, Abu-Elmagd K, et al. Intestinal transplantation under tacrolimus monotherapy after perioperative lymphoid depletion with rabbit antithymocyte globulin (thymoglobulin). Am J Transplant 2005; 5: 1430-6

20. Debray D, Furlan V, Baudouin V, et al. Therapy for acute rejection in pediatric organ transplant recipients. Pediatr Drugs 2003; 5 (2): 81-93
21. LaCorcia G, Swistak M, Lawendowski C, et al. Polyclonal rabbit antithymocyte globulin exhibits consistent immunosuppressive capabilities beyond cell depletion. Transplantation 2009 Apr 15; 87 (7): 966-74

22. 2009 OPTN/SRTR annual report: transplant data 2009. Annual report of the U.S. Organ Procurement and Transplantation Network and the Scientific Registry of Transplant Recipients. Rockville (MD): US Department of Health and Human Services, Health Resources and Services Administration, Health Care Systems Bureau, Division of Transplantation, 2009

23. Mazariegos GV, Steffick DE, Horslen S, et al. Intestine transplantation in the United States, 1999-2008. Am J Transplant 2010 Apr; 10 (4 Pt 2): 1020-34

24. Tzakis AG, Kato T, Nishida $\mathrm{S}$, et al. Alemtuzumab (Campath-1H) combined with tacrolimus in intestinal and multivisceral transplantation. Transplantation 2003; 75: 1512-7

25. Tzakis AG, Kato T, Nishida S, et al. Preliminary experience with campath $1 \mathrm{H}$ $(\mathrm{C} 1 \mathrm{H})$ in intestinal and liver transplantation. Transplantation 2003; 75: 1227-31

26. Bond GJ, Mazariegos GV, Sindhi R, et al. Evolutionary experience with immunosuppression in pediatric intestinal transplantation. J Pediatr Surg 2005; 40: 274-9; discussion 279-80

27. Kato T, Tzakis AG, Selvaggi G, et al. Intestinal and multivisceral transplantation in children. Ann Surg 2006 Jun; 243 (6): 756-64; discussion 764-6

28. Goulet O, Sauvat F, Ruemmele F, et al. Results of the paris program: ten years of pediatric intestinal transplantation. Transplant Proc 2005; 37: 1667-70

29. Fishbein TM, Florman S, Gondolesi G, et al. Intestinal transplantation before and after the introduction of sirolimus. Transplantation 2002 May 27; 73 (10): $1538-42$

30. Fishbein TM, Kaufman SS, Florman SS, et al. Isolated intestinal transplantation: proof of clinical efficacy. Transplantation 2003; 76 (4): 636-40

31. Starzl TE. Immunosuppressive therapy and tolerance of organ allografts. N Engl J Med 2008 Jan 24; 358 (4): 407-11

32. Starzl TE, Zinkernagel RM. Transplantation tolerance from a historical perspective. Nat Rev Immunol 2001 Dec; 1 (3): 233-9

33. Abu-Elmagd KM, Costa G, Bond GJ, et al. Five hundred intestinal and multivisceral transplantations at a single center: major advances with new challenges. Ann Surg 2009; 250: 567-81

34. Mazariegos GV, Squires RH, Sindhi RK. Current perspectives on pediatric intestinal transplantation. Curr Gastroenterol Rep 2009; 11: 226-33

35. Pirenne J, Kawai M. Intestinal transplantation: evolution in immunosuppression protocols. Curr Opin Organ Transplant 2009; 14 (3): 250-5

36. Mazariegos GV, Soltys K, Bond G, et al. Pediatric intestinal retransplantation: techniques, management, and outcomes. Transplantation 2008 Dec 27; 86 (12): $1777-82$

37. Ojo AO, Held PJ, Port FK, et al. Chronic renal failure after transplantation of a nonrenal organ. N Engl J Med 2003; 349: 931-40

38. Ueno T, Kato T, Gaynor $\mathbf{J}$, et al. Renal function after pediatric intestinal transplant. Transplant Proc 2006 Jul-Aug; 38 (6): 1759-61

39. Ueno T, Kato T, Gaynor J, et al. Renal dysfunction following adult intestinal transplant under tacrolimus-based immunosuppression. Transplant Proc 2006 Jul-Aug; 38 (6): 1762-4

40. Abu-Elmagd KM, Mazariegos G, Costa G, et al. Lymphoproliferative disorders and de novo malignancies in intestinal and multivisceral recipients: improved outcomes with new outlooks. Transplantation 2009 Oct 15; 88 (7): 926-34

41. Reyes J, Mazariegos GV, Bond GM, et al. Pediatric intestinal transplantation: historical notes, principles and controversies. Pediatr Transplant 2002 Jun; 6 (3): 193-207

42. Botija G, Ybarra M, Ramos E, et al. Autoimmune cytopaenia after paediatric intestinal transplantation: a case series. Transpl Int 2010; 23 (10): 1033-7

43. Lacaille F, Moesb N, Hugotc J-P. Severe dysimmune cytopenia in children treated with tacrolimus after organ transplantation. Am J Transplant 2006; 6: $1072-6$ 
44. Dierickx D, Monbaliu D, De Rycke A, et al. Thrombotic microangiopathy following intestinal transplantation: a single center experience. Transplant Proc 2010 Jan-Feb; 42 (1): 79-81

45. Paramesh AS, Grosskreutz C, Florman SS, et al. Thrombotic microangiopathy associated with combined sirolimus and tacrolimus immunosuppression after intestinal transplantation. Transplantation 2004 Jan 15; 77 (1): 129-31

46. Humar A, Jessurun J, Sharp HL. Hemolytic uremic syndrome in small bowel transplant recipients: the first two case reports. Transpl Int 1999; 12 (5): 387-90

47. Langnas AN, Shaw Jr BW, Antonson DL, et al. Preliminary experience with intestinal transplantation in infants and children. Pediatrics 1996; 97 (4): 443-8

48. Fryer J, Grant D, Jiang J, et al. Influence of macrophage depletion on bacterial translocation and rejection in small bowel transplantation. Transplantation 1996; 15: 553-9

49. Bond G, Reyes J, Mazariegos G, et al. The impact of positive T-cell lymphocytotoxic crossmatch on intestinal allograft rejection and survival. Transplant Proc 2000 Sep; 32 (6): 1197-8
50. Sindhi R, AshokKumar C, Mazariegos G, et al. Immune monitoring in small bowel transplantation. Curr Opin Organ Transplant 2010 Jun; 15 (3): 349-56

51. Gondolesi G, Blondeau B, Aurette R, et al. Pretransplant immunomodulation of highly sensitized small bowel transplant candidates with intravenous immune globulin. Transplantation 2006 Jun 27; 81 (12): 1743-6

52. Everly MJ. A summary of bortezomib use in transplantation across 29 centers. Clin Transpl 2009: 323-37

53. Ishii T, Mazariegos GV, Bueno J, et al. Exfoliative rejection after intestinal transplantation in children. Pediatr Transplant 2003 Jun; 7 (3): 185-91

54. Nayyar N, Mazariegos G, Ranganathan S, et al. Pediatric small bowel transplantation. Semin Pediatr Surg 2010 Feb; 19 (1): 68-77

Correspondence: Dr George V. Mazariegos, MD, FACS, Hillman Center for Pediatric Transplantation, Children's Hospital of Pittsburgh of UPMC, One Children's Hospital Drive, 4401 Penn Avenue, Faculty Pavilion, Floor 6, Pittsburgh, PA 15224, USA.

E-mail: george.mazariegos@chp.edu 